\title{
Study of Overseas Testing Experience and Future Directions
}

\author{
Jian Xiang \\ School of Information and Electronic Engineering, Zhejiang University of Science and Technology, Hangzhou, \\ China \\ Email: freexiang@gmail.com
}

Received December 2013

\begin{abstract}
The project will draw examination experience from overseas universities and colleges, form the integrated evaluation system of four-element module throughout the whole process of education, i.e. the innovation talent evaluation system of integrating "normal results, practice assessment, review test and oral test", adhere to integrated, multi-oriented, open and scientific principles, and truly and comprehensively implement the function of an examination system.
\end{abstract}

\section{Keywords}

Examination, Oversea, Evaluation System, Four-Element Module

\section{Introduction}

Colleges and universities are regarded as the main bearer of innovation in education by society, but innovative education should be run through the entire process of education [1]. Extending the concept of innovation cannot be understood solely as personnel engaging in cutting-edge scientific research, or requiring that all walk in the forefront of the world, which is unrealistic at present for our country [2]. Personnel engaging in innovating are not limited to a small number of scientists at frontier. There are many forms of innovation, which not only refers to invention and creation, but also introduction and absorption [3]. Making patents into products is a kind of innovation as well as process improvement. Innovation is not just confined to the high precision and advanced areas of research, it also reflects in practical work from all walks of life. If the society forms such a kind of consciousness that everything can be innovative, each industry may lead to creative talents, and the community will show respect to individual achievements in any industry, then the students can find their own position, and they may be likely to be innovative [4] [5].

In 1990, China and Germany began a formal exchange of letters between the two governments for co-constructing our university. At present, there is a new round of province-state and inter-school cooperation projects. Such projects constantly expand the depth and breadth of cooperation between our school and University of Applied Sciences in Germany. In that country, it has been nearly 30 years of innovative education through cooperating with enterprises [6]. And it is a highly effective combination of teaching and learning. In recent years, our university has begun to draw more educational experience in-depth from the University of Applied Sciences in Germany, promote the "three projects", persist in carrying on the strategy of "Strengthening the school with 
high teaching quality [7], excellent talents and cooperation”, develop high-level application-oriented talents in the context of internationalization, push forward talent project with university-enterprise cooperation project and provide impetus for quality engineering. The undergraduate teaching of computers, electronics, communications and other types of professional information technology must be based on the innovative training mode on applying abilities, i.e. how to analyze and solve problems. It is necessary to change the assessment structure of theoretical and practical courses and deepen the practice of professional application knowledge. The focus of test should be on the ability of analyzing and solving problems. Learning from a series of test experience, and then devoting ourselves into the reform of assessment system, the competitiveness of engineering applied talents will be enhanced finally.

\section{Hypothesis and Proposed Innovations}

First, confirm that you have the correct template for your paper size. This template has been tailored for output on the custom paper size $(21 \mathrm{~cm} * 28.5 \mathrm{~cm})$. To give full play to the advantages of 20-year international cooperation with the University of Applied Sciences in Germany, we learn from their practice teaching evaluation system and implementation experience, so that the content of practice teaching assessment can track the development of disciplines and curriculum timely, and then we may explore the teaching reform path of applied innovative talents' practical ability evaluation system for colleges and universities. The research of examination experience from overseas universities and colleges and future direction provides references for the reform of examination evaluation system. First of all, we should change traditional concept of examination, establish talent quality view in Knowledge Economy Age, cultivate talents on the basis of quality education and innovation, take the cultivation of innovative spirit and ability as a center, and establish assessment mechanism which combines broadening knowledge, building ability and improving quality as a whole. Second, we should change the examination model of integrating teaching, examination and assessment, establish a scientific and fair examination operation mechanism, reform contents and methods of examination, promote the combination of diversity and openness, increase oral test appropriately, establish a scientific scoring system and student's comprehensive evaluation system, adhere to the combination of formative and summative test, explore the modes of combining "four meta-module comprehensive examination" with "test comments", perfect the appraisal system for evaluating qualified personnel with university-enterprise cooperation, invite technical experts in the enterprise, teachers and students carry out practical projects teaching in the enterprise, reform the form of experimental curriculum examinations and professional curriculum settings, make it plays a role in the educational goals of developing high-quality engineering talents, and cultivate talents the enterprise needs. In order to establish assessment model of university-enterprise cooperation, institutionalization, and innovative practice evaluation system, experimental teaching should follow the development of disciplines and curriculums timely, and promote reform of teaching in different ways.

The project will draw examination experience from overseas universities and colleges, form the integrated evaluation system of four-element module throughout the whole process of education, i.e. the innovation talent evaluation system of integrating "normal results, practice assessment, review test and oral test", adhere to integrated, multi-oriented, open and scientific principles, and truly and comprehensively implement the function of an examination system.

\section{Methods, Technical Routes and Implementation Steps}

The study of overseas testing experience and future direction will be primarily through building six platforms for the implementation and improvement, i.e. evaluation platform for superior curriculum, international teaching, individualized teaching, cultural quality education, and innovative practice. Updating the guidance for appraisal system is conductive for industries in Zhejiang Province to discover and develop young talents to master professional skills, and help lead them to professional road. At each stage, instructors give guidance on direction and tips on methods through the assessment system without telling students what to do directly.

The research methods combine Chinese traditional education thought with overseas modern examination system, and closely integrate scientific and engineering practice with talents cultivation, which make educational concepts, contents, methods and assessment means adapt to the requirements of the progress, technological innovation and people's overall development. We should attach great importance to and actively promote the reform and innovation of the assessment mode for applied undergraduate engineering talents. Besides, it should 
be overall designed and realized step by step. It is also emphasized that researching the actual needs of the community to high-quality innovative talents and learning successful experience from the University of Applied Sciences in Germany are important to adjust and improve the assessment methods design and evaluation standard system of applied undergraduate engineering talents education, and establish a research-oriented appraisal system. Starting from the policy system, establishing an open, mobile, competitive and collaborative research mechanism and improving the incentive mechanism can make the evaluation system be constantly updated.

An efficient evaluation system must be established among all teachers and students who have updated the real concept of education. It is the overall performance of overall level of the university and the ability of training personnel. Technical routes: the first is to construct systematically and penetrate fully, i.e. the main line of innovative training should be run through the whole course of developing talents and assessment, systematic reform and overall construction should be carried out in the key links of the assessment, the previous problems of incompletely reforming, limited foothold, single path, small coverage and one test determining one's fate etc. should be solved, and the prospects of running through the main line, full penetration, full participation and all benefit should be achieved. The second route is multi-dimensional interaction and students-centered. We should focus on innovation assessment and opening disciplines orderly. Interacting with students and extending the assessment may be realized through "accessing to conditions and facilities, experiencing scientific process, converting scientific and technological resources and nurturing academic atmosphere”. Besides, overall optimization of courses can be also realized through "curriculum reform, curriculum resources establishment, laboratory education reform, and methods and means updating" to interact with students and extend the assessment. Moreover, teachers should invest actively, and through "classroom teaching innovation, science and technology project mentor, excellent typical demonstration, research experience guidance” can realize interacting with students and extending the assessment. The character of student-centered is obvious and it can be through "hobby-oriented, individual choosing flexibly, self-system planning, independent practice" to implement innovation assessment. The third one is the combination of soft and hard and system impelling.

Implementation steps: establish "innovation evaluation system", "innovative education base operating system" and other series of management systems and operating mechanisms. Meanwhile, an overall improvement of teaching laboratory and the opening of innovative educational base provide superior hardware platform for students' innovative practice. 1) To establish innovative design laboratories and cooperation base of university-enterprise joint training need the introduction of the enterprise and the project to explore a new model of experimental innovative teaching evaluation. Students' ability to practice their own hands can be improved with the project to assess. 2) The implementation of practicing semester formative assessment needs broadening the significance of innovative experimental base for university-enterprise cooperation, reforming the practice of the second semester, and establishing assessment model of university-enterprise cooperation. 3) Setting up project assessment of innovative practice should strengthen the cooperation with large companies from IT industry in Zhejiang Province with the university-enterprise cooperation mode, and the practice of researching on curriculum teaching evaluation. 4) Innovating the Labs open management requires the use of information technology and computer management, the establishment of an open laboratory management system, the multi-core programming innovation laboratories and other open laboratories in order to achieve dynamic and open management of experimental course teaching. 5) Promoting international examination system reform of computer engineering technology is to develop students' ability to survive in the social environment of internationalization and multi-culture. 6) To form a teaching program and assessment platform network which is completely in line with innovative and practical ability training system.

\section{Experimental Results}

Marked by three results: 1) built a multi-level and modular curriculum examination system on the basis of advanced laboratory teaching philosophy and three capacity-building objectives, and formed the core of the reform of teaching practice, 2) constructed an open lab environment and modern management system, and introduced the project assessment of teaching practice, 3) reformed experimental evaluation methods and models, and formed a multi-cultural self-assessment model based on innovation ability training. The results were adopted in the university, and we set up 13 experimental courses for electronic information, communication, computer, automation, electrical and mechanical and other professions. The experimental evaluation of information technology involved only five professions before the study. Students' overall practice and innovation ability improved 
significantly since the study and application of the results. In recent years, students guided by members in the research group achieved good results continuously in science and technology competitions. In December 2008, they won the first prize of bipedal robot walkers cross footprint in the University group at the Tenth Chinese Robot Competition and RoboCup Open Tournament and won the second prize of bipedal robot walkers narrow set of footprints in the University group. The award-winning students were reported by "Qian Jiang Evening News". They also obtained the best results in history on the fifth University Programming Contest in Zhejiang in May 2008, the National Collegiate Programming Invitational Tournament in October 2008, and Undergraduate Electronic Design Contest in Zhejiang Province in September 2008.

\section{References}

[1] Zhang, B., Huai, H.Y., Du, K., et al. (2007) A Testing System for Formative Experimental Teaching under Network Conditions. Researches in Higher Education of Engineering, 4, 112-115.

[2] Sun, X.Q. (2005) On the Transformation of Teachers' Roles and Improvement of Information Literacy in On-Line Teaching. Research in Education Development, 91, 87-88.

[3] Liu, Y.F. The Misconception of Bilingual Teaching in Higher Education and Its Solutions. Research in Higher.

[4] Guo, Q. (2006) Problems and Countermeasures for Bilingual Education in Local Universities. Journal of Shaoguan University, 2, 342-348.

[5] Jiang, J. (2006) Discussion on Bilingual Teaching of Economics and Management Courses in Colleges and Universities. China Adult Education, 6, 455-459.

[6] Liang, Y. (2006) Status of Bilingual Teaching in Colleges and Universities and the Countermeasures. Heilongjiang Education (Higher Education Research \& Appraisal), 5, 465-468.

[7] Yao, X.Y. (2006) Discussion on the Construction of the Teaching Materials for the Bilingual Teaching. Sci/Tech Information Development \& Economy, 7, 576-582. 